\title{
Connectivity-Mediated Ecohydrological Feedbacks and Regime Shifts in Drylands
}

\author{
Angeles G. Mayor, ${ }^{1,2 *} \odot$ Susana Bautista, ${ }^{3}$ Francisco Rodriguez, ${ }^{4}$ and \\ Sonia Kéfi ${ }^{2}$
}

\begin{abstract}
${ }^{1}$ Copernicus Institute of Sustainable Development, Environmental Science Group, Utrecht University, P.O. Box 80115, 3508 TC Utrecht, The Netherlands; ${ }^{2}$ ISEM, CNRS, Université de Montpellier, IRD, EPHE, Montpellier, France; ${ }^{3}$ Department of Ecology and IMEM, University of Alicante, Apdo. 99, 03080 Alicante, Spain; ${ }^{4}$ Department of Applied Mathematics, University of Alicante, Apdo. 99, 03080 Alicante, Spain
\end{abstract}

\begin{abstract}
Identified as essential mechanisms promoting alternative stable states, positive feedbacks have been the focus of most former studies on the potential for catastrophic shifts in drylands. Conversely, little is known about how negative feedbacks could counterbalance the effects of positive feedbacks. A decrease in vegetation cover increases the connectivity of bare-soil areas and entails a global loss of runoff-driven resources from the ecosystem but also a local increase in runoff transferred from bare-soil areas to vegetation patches. In turn, these global resource losses and local resource gains decrease and increase vegetation cover, respectively, resulting in a global positive and a local negative feedback loop. We propose that the interplay of these two interconnected ecohydrological feedbacks of opposite sign determines the vulnerability of dryland ecosystems to catastrophic shifts. To test this hypothesis, we developed a spatially explicit model and assessed the effects of varying combinations of feedback strengths
\end{abstract}

on the dynamics, resilience, recovery potential, and spatial structure of the system. Increasing strengths of the local negative feedback relative to the global positive feedback decreased the risk of catastrophic shifts, facilitated recovery from a degraded state, and promoted the formation of banded vegetation patterns. Both feedbacks were most relevant at low vegetation cover due to the nonlinear increase in hydrological connectivity with decreasing vegetation. Our modelling results suggest that catastrophic shifts to degraded states are less likely in drylands with strong source-sink dynamics and/or strong response of vegetation growth to resource redistribution and that feedback manipulation can be useful to enhance dryland restoration.

Key words: alternative stable states; catastrophic shifts; dryland restoration; negative feedbacks; positive feedbacks; spatially explicit model; vegetation pattern.
Received 12 July 2018; accepted 21 January 2019; published online 22 April 2019

Authors' Contribution AGM and SB conceived the idea; AGM performed the research and analysed the data; and all authors contributed to the design of the study, the development of the model, and the writing of the paper.

*Corresponding author; e-mail: a.garciamayor@uu.nl

\section{HighLIGHTS}

- Two ecohydrological feedbacks of opposite sign modulate regime shifts in drylands.

- Sudden regime shifts are unlikely when patchscale negative feedbacks dominate.

- Increasing the strength of negative ecohydrological feedbacks favours restoration. 


\section{INTRODUCTION}

Drylands face the challenge of accommodating and providing services to a large and increasing fraction of the global population in a context of restrictive climatic conditions and limited natural resources. It is estimated that $10-20 \%$ of the world drylands are severely degraded and the ongoing global change is expected to further increase human and climatic pressures on drylands and hence the risk of desertification (MEA 2005; Middleton and Sternberg 2013; IPCC 2014; Prăvălie 2016). Understanding the factors and mechanisms that govern dryland dynamics, in particular the risk of sudden regime shifts to a degraded state and the recovery potential from this degradation, is therefore of utmost importance.

Theory and observations have suggested that drylands could experience catastrophic shifts from comparatively healthy to degraded states in response to gradual increases in human-induced and/ or climatic pressure (von Hardenberg and others 2001; Scheffer and Carpenter 2003; Rietkerk and others 2004; Kéfi and others 2007a, b; Bestelmeyer and others 2011; Gao and others 2011; Mora and Lázaro 2013). Decreasing the pressure levels to the ones prior to the shift can be insufficient to recover the healthy state; in this case, degradation and recovery pathways differ (that is, hysteresis) because two alternative stable ecosystem states coexist for a certain range of environmental conditions (that is, bistability). A stable state is typically reinforced by internal feedbacks, which regulate their response to changes in environmental conditions and confer the system the capacity to absorb a certain magnitude of disturbance or stress without shifting to an alternative state (that is, resilience).

Feedbacks are positive when the reciprocal effects of the elements in the feedback loop have the same sign, either positive or negative. They are then self-reinforcing feedbacks and amplify changes in the state variables (DeAngelis and others 1986; Lenton 2013). Strong positive feedbacks are a necessary, but not sufficient, requirement for alternative stable states (May 1977; Rietkerk and others 1996; Scheffer 2009; Kéfi and others 2016), with shifts between states occurring when a control variable passes a threshold level and triggers a change in the direction of the positive feedback, pushing the system towards a different attractor, towards a new stability domain (Scheffer and others 2001). In drylands, positive feedbacks between vegetation growth and water transport towards the growing vegetation patch explain shifts between vegetated and bare soils when external conditions reduce patch biomass below a critical threshold (Rietkerk and van de Koppel 1997; Meron 2016). At the landscape scale, positive feedbacks between decreasing vegetation cover and processes such as increasing erosion, decreasing precipitation mediated by changes in albedo, and increasing heterogeneity in soil resources are often invoked as mechanisms giving rise to catastrophic shifts towards degraded states in drylands (Otterman 1977; Schlesinger and others 1990; Rietkerk and van de Koppel 1997; Davenport and others 1998; Briske and others 2006; Lenton 2013; Mayor and others 2013). Conversely, negative feedbacks (that is, with reciprocal effects differing in sign) such as increasing competition with increasing plant cover, which constrains further increase in plant cover, are selfcorrecting feedbacks that tend to dampen the impact of environmental changes and disturbances, and contribute to stabilize the state variables around equilibrium points. Multiple positive and negative feedbacks are interconnected and operate simultaneously in ecosystems, often at different spatial scales and involving different hydrological, biogeochemical, and ecological processes (Rietkerk and van de Koppel 2008; Svejcar and others 2014). The relative importance of these feedbacks may change across environmental gradients and ecosystem types, which adds uncertainty to predictions on the magnitude and direction of the response of major ecosystem pools and fluxes to climatic and human-induced changes (Waddington and others 2015). Combining self-correcting (negative) and self-reinforcing (positive) feedbacks has been explicitly or implicitly considered in several models and conceptual frameworks of ecosystem dynamics (Lejeune and others 2002; Briske and others 2006; Rietkerk and van de Koppel 2008; Turnbull and others 2012; Stewart and others 2014). However, their relative role and the effects of variations in their respective strengths on the ecosystem response to environmental changes, including the potential for catastrophic shifts, have not yet been investigated.

In drylands, as water-limited ecosystems, ecohydrological processes are critical to ecosystem functioning (Rodriguez-Iturbe 2000; Whitford 2002). We propose that vegetation cover and pattern in drylands, and thus ecosystem functioning and state, are controlled by the interplay of two main ecohydrological feedbacks mediated by baresoil connectivity that operate at different scales (Figure 1). At the ecosystem scale, a positive feedback links vegetation cover and resource conservation, so that changes in vegetation cover that 
increase the size and connectivity of bare-soil areas (that is, runoff-source areas), and thus the production of runoff and sediments, would increase the global loss of resources from the ecosystem (Bautista and others 2007; Mayor and others 2008; García-Fayos and others 2010; Turnbull and others 2010; Urgeghe and others 2010), which in turn would reduce the overall plant productivity and the vegetation cover and increase the bare-soil connectivity, closing the positive loop (global positive feedback, Figure 1). However, an increase in baresoil connectivity also entails an increase in the potential amount of runoff transferred from baresoil areas to vegetation patches, which would lead to local gains of resources at the patch scale and enhance plant growth (Puigdefabregas and others 1999; Ludwig and others 2005; King and others 2012; Espigares and others 2013; Urgeghe and Bautista 2015), and in turn increase vegetation cover and decrease bare-soil connectivity, completing a negative feedback loop (local negative feedback, Figure 1). Considering this conceptual framework, we hypothesized that the net effect of global positive and local negative ecohydrological feedbacks determines the vulnerability of dryland ecosystems to catastrophic shifts, so a higher strength of the global feedback would drive the systems to sudden regime shifts, whereas a higher strength of the local feedback would contribute to both prevent those shifts and facilitate the recovery of degraded drylands. Also, given the intrinsic directional nature of the processes mediated by hydrological connectivity, in particular of the local transfer of resources from bare-soil areas to downslope patches, a higher strength of the local feedback would promote a higher degree of aniso-

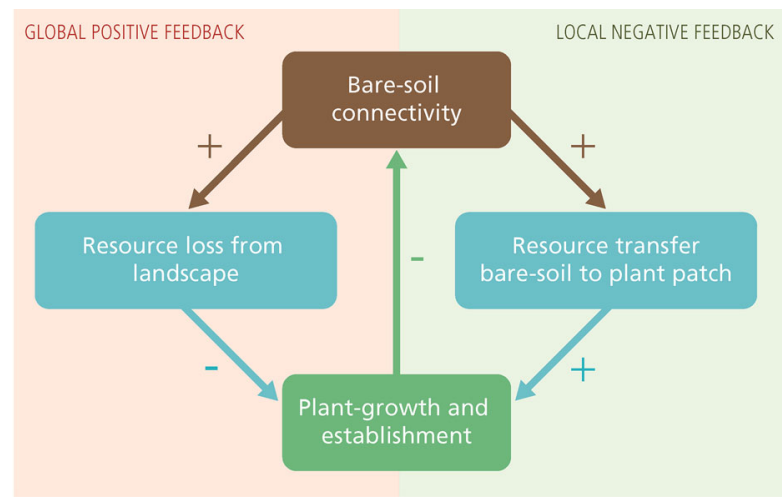

Figure 1. Ecohydrological feedbacks between bare-soil connectivity, runoff-driven resource redistribution, and vegetation growth at the ecosystem (global positive feedback, left) and at the vegetation patch scales (local negative feedback, right). tropy (that is, formation of bands) in the resulting spatial pattern of vegetation cover.

To test these hypotheses, we developed a spatially explicit model that interconnects the dynamics of vegetation cover and spatial pattern with the potential redistribution of resources driven by the hydrological connectivity of the dryland ecosystem. We built our model on a previous probabilistic cellular automaton of dryland vegetation dynamics (Kéfi and others 2007b) that already included a local positive feedback between plant establishment and microsite amelioration by neighbouring vegetation, a crucial process in dryland ecosystems (Callaway 2007). Our model additionally includes the double-feedback loop depicted in Figure 1: a global positive feedback and a local negative feedback between changes in baresoil connectivity and vegetation growth at the ecosystem and at the vegetation patch scales, respectively, and considers the directional nature of the redistribution of resources by water.

Using our modelling framework, we investigated how different strengths of positive and negative scale-dependent ecohydrological feedbacks influence (1) dryland dynamics and potential for catastrophic regime shifts along gradients of environmental conditions, (2) ecosystem resilience, measured as the amount of pressure that the ecosystem can stand without shifting to a degraded state, (3) recovery potential, measured at the threshold environmental conditions required for triggering the recovery from a degraded state, and (4) the spatial pattern of the vegetation at steady state.

\section{MethodS}

\section{Modelling Connectivity-Mediated Feedbacks in Drylands}

We developed a spatially explicit model to assess the potential effects of the interplay of varying strengths of positive and negative ecohydrological feedbacks on dryland response to environmental pressure. The model builds on a probabilistic cellular automaton developed by Kéfi and others (2007b) that represents a dryland ecosystem by a square lattice in which cells can be found in three possible states: vegetated $(+)$, empty $(0)$, or degraded (-). Empty cells represent bare-soil areas with soils suitable for plant colonization, while degraded cells represent eroded soils where plants cannot establish. Degraded cells need to have regenerated before they can be colonized by vegetation, and thus the transition $(-) \rightarrow(+)$ is not 
allowed. The model represents local facilitation (that is, biophysical processes in the neighbourhood of a plant that favours the establishment of other plants) as an increased regeneration rate of degraded cells when they are in the neighbourhood of vegetated cells. The transitions between the cell states are as follows: the mortality of vegetated cells $((+) \rightarrow(0))$, the degradation of empty cells, $((0) \rightarrow(-))$, the regeneration of degraded cells $((-) \rightarrow(0))$, and the colonization of empty cells $((0) \rightarrow(+))$, which occur, respectively, at the following rates

$$
\begin{gathered}
w_{\{+, 0\}}=m, \\
w_{\{0,-\}}=d, \\
w_{\{-, 0\}}=r+f \cdot q_{+\mid-}, \\
w_{\{0,+\}}=\left[\delta \cdot \rho_{+}+(1-\delta) \cdot q_{+\mid 0}\right]\left(b-c \cdot \rho_{+}\right) .
\end{gathered}
$$

The parameters of the model and the values of the parameters used in this work are reported in Table 1. A more detailed description of the baseline cellular automata model used in this work can be found at Kéfi and others (2007a, b).

We included ecohydrological feedbacks between resource redistribution and changes in plant cover by making plant establishment on an empty cell dependent on both the positive and negative effects of bare-soil connectivity (Figure 1). To quantify bare-soil connectivity, we used Flow- length, a well-known connectivity metric that is being increasingly used as an indicator of hydrological connectivity and ecosystem functioning in drylands (Liu and others 2013; Muñoz-Robles and others 2013; Okin and others 2015) and that has been successfully tested against water and soil loss measurements at the slope and catchment scales (Mayor and others 2008). Flowlength calculates the length of the potential runoff pathways in a landscape considering both vegetation pattern and topography, assuming that bare-soil areas (that is, empty or degraded cells in the model) are sources of runoff and sediments that are trapped by downslope vegetated areas (see Mayor and others 2008 for further details). The degree of upslope hydrological connectivity of each cell (hereafter, local connectivity), calculated as the sum of the lengths of the runoff pathways that leave each and all upslope bare-soil cells and that reach the cell (Figure 2), was used as a proxy for the potential amount of resources arriving to the cell as carried by runoff. The hydrological connectivity of the whole system (hereafter, global connectivity), calculated as the average length of the runoff pathways that leave each and all bare-soil cells in the lattice (Figure 2), was used as a surrogate of the net loss of resources.

The negative influence of the net loss of resources from the system (global connectivity) on

\begin{tabular}{|c|c|c|}
\hline Symbol & Definition & Value \\
\hline$\rho_{+}$ & Density of vegetated sites & \\
\hline$q_{\mathrm{i} \mid j}$ & Probability of finding a site $i$ in the neighbourhood of a site in state $j$ & \\
\hline$m$ & Mortality probability of a vegetated site & 0.2 \\
\hline$f$ & $\begin{array}{l}\text { Local facilitation strength: maximum effect of a neighbouring vegetated site on the regeneration of a } \\
\text { degraded site }\end{array}$ & 0.9 \\
\hline$\beta$ & Intrinsic seed production rate per vegetated site; "survival probability", "germination probability" & \\
\hline$\epsilon$ & Establishment probability of seeds on an empty site in a system without competition & \\
\hline$b$ & $\begin{array}{l}\text { Establishment probability of plants on an empty site in a system without competition }(=\beta \epsilon) \text {. Measures } \\
\text { the severity of the environmental conditions; a lower } b \text { value reflects a higher aridity level }\end{array}$ & $0-1$ \\
\hline$\delta$ & Fraction of seeds globally dispersed & 0.1 \\
\hline$g$ & Competitive effect of the global density of vegetated sites on the establishment of new individuals & \\
\hline$c$ & $\beta \mathrm{g}$ & 0.2 \\
\hline$r$ & Regeneration probability of a degraded site without vegetation in its neighbourhood & 0.01 \\
\hline$d$ & Degradation probability of empty sites & 0.1 \\
\hline$\alpha$ & Strength of feedback between plant functioning and vegetation pattern via the global loss of resources & $0-1$ \\
\hline$\gamma$ & Strength of feedback between plant functioning and vegetation pattern via the local gain of resources & $0-1$ \\
\hline FL & Flowlength index & $0-26.7$ \\
\hline $\mathrm{FL}_{\max }$ & Maximum value of the global connectivity & 26.7 \\
\hline flveg $_{\max }$ & Maximum value of the local connectivity of neighbour vegetated cells & 7901.5 \\
\hline
\end{tabular}
plant establishment, and hence on the increase in vegetation cover, was included in the model as:

Table 1. Parameters of the Model and Values of the Parameters Used in this Work 


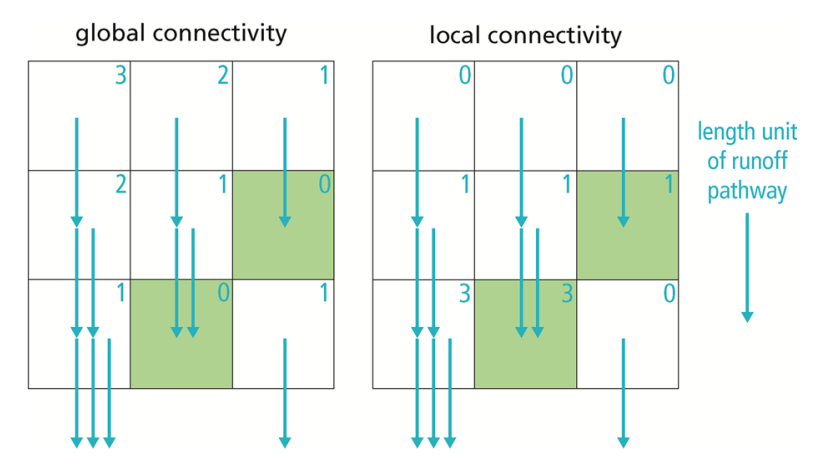

Figure 2. Schematic representation of the global and local connectivity for a hypothetical lattice of $3 \times 3$ cells on a planar slope. Green cells are vegetation, and white cells are (empty or degraded) bare soil. The number in each cell represents either the length of the runoff pathway that leave the cell (Global connectivity) or the sum of the lengths of the runoff pathways that reach the cell (local connectivity). Global connectivity has a single value for the whole lattice and is calculated as the average length of the runoff pathways that leave each and all cells in the lattice. Vegetated cells are assumed to be runoff sinks, and as such, the length of their runoff pathway is always zero. In this example global connectivity is 1.22 length units $((3+2+1+2+1+$ $0+1+0+1) / 9)$. Local connectivity has a value for each cell that is calculated as the sum of the lengths of the runoff pathways that leave each and all upslope bare-soil cells and that reach the cell. Only local connectivity values of vegetated cells ( 1 and 3 length units in the given example) are used in the model (Eq. 6). The arrows point in the flow direction (Color figure online).

$$
b^{\prime}=b \cdot\left(1-\alpha \cdot \frac{F L}{F L_{\max }}\right),
$$

where $b^{\prime}$ is the plant establishment affected by the global loss of resources from the system; $b$ is the potential plant establishment, as defined in the original model (Kéfi and others 2007b); $\alpha$ modulates the dependence of plant establishment on the global connectivity, and thus it represents the strength of the global feedback (left feedback in Figure 1); FL is the global connectivity; and $\mathrm{FL}_{\max }$ is the maximum value of the global connectivity, which is obtained from a lattice without vegetated cells and thus with a maximum runoff potential. Plant establishment is negatively affected by increased global connectivity when $\alpha>0$. The positive influence of the transfer of resources from bare-soil areas to vegetation patches on plant establishment and patch growth was modelled as:

$$
b^{\prime \prime}=b^{\prime}+\gamma\left(1-b^{\prime}\right) H\left(\frac{\text { flveg }}{\text { flveg }_{\max }}\right)
$$

where $b^{\prime \prime}$ is plant establishment affected by both the local gain and the global loss of resources; $\gamma$ modulates the dependence of plant establishment on the local connectivity, and thus, it represents the strength of the local feedback (right feedback in Figure 1); flveg is the sum of the local connectivity of the vegetated cells in the 8-neighbourhood (cumulative local connectivity); flveg max $_{\text {ax }}$ is the maximum cumulative local connectivity in the lattice; and $H(x)$ is a saturation function such that:

$$
H(x)=\left\{\begin{array}{l}
3 x, \quad x<\frac{1}{3} \\
1, \quad x \geq \frac{1}{3}
\end{array}\right.
$$

Plant establishment is positively affected by increased connectivity when $\gamma>0$. The values of FL, $\mathrm{FL}_{\max }$, flveg, and flveg $\max$ depend on the topographic parameterization of the lattice, which together with the spatial distribution of the vegetated cells is needed to calculate the length of the runoff flowpaths with Flowlength. In this work, we considered a lattice of $100 \times 100$ cells of size $0.5 \times 0.5 \mathrm{~m}^{2}$ (that is, size of an average adult plant individual) on a planar slope with an angle of $20^{\circ}$. For a planar slope lattice, the maximum cumulative local connectivity of neighbouring vegetated cells (flveg max $_{\text {ax }}$, considering an 8-neighbourhood, corresponds to the sum of the flowpaths arriving to three vegetated cells each located at the last row of three bare-soil columns.

\section{Simulation Experiments and Data Analyses}

We simulated gradients of increasing and decreasing environmental pressure, representing degradation and recovery pathways, respectively, and evaluated the model outcomes for different combinations of strengths of the global and local connectivity feedbacks ( $\alpha$ and $\gamma$, respectively). The gradients of environmental pressure were simulated by varying values of the potential plant establishment $(b)$, used as a surrogate of the quality of the environmental conditions (higher $b$ meaning better conditions and thus lower pressure). For each value of $b$, the simulations for the degradation pathway started from high vegetation cover (random distribution of $90 \%$ vegetated cells, $5 \%$ empty cells, and 5\% degraded cells) and the simulations of the recovery pathway started from low vegetation cover (random distribution of $1 \%$ vegetated cells, $9 \%$ empty cells, and 90\% degraded cells). Simulations were run until steady state for both vegetation cover and global hydrological connectivity (that is, FL). For each combination of $b, \alpha$, and $\gamma$, we assessed the ecosystem steady state (measured as 
the proportion of vegetated cells in the steady-state lattice), the minimum value of environmental pressure $(b)$ for which equilibrium vegetation cover is higher than $1 \%$ (which we define as a cover threshold for full degradation) along both the degradation and recovery pathways $\left(b_{\mathrm{deg}}\right.$ and $b_{\text {rec }}$, respectively); these two values of $b$ form the boundary of environmental pressure for which the system is bistable. The model is not deterministic, and thus the simulation results for a given combination of parameters vary, in particular when approaching a sudden shift. For this reason, for each parameter combination, we repeated the simulation 20 times to more accurately describe the system behaviour estimating $b_{\text {deg }}$ from the average of the 20 values and $b_{\text {rec }}$ as the minimum $b$ value for which vegetation cover is higher than $1 \%$ for at least $50 \%$ of the simulation repetitions. For parameter combinations not showing recovery under optimal environmental conditions $(b=1)$ in at least $50 \%$ of the simulation repetitions, $b_{\text {rec }}$ was not estimated.

To quantify the effects of $\alpha$ and $\gamma$ combinations on the spatial patterns of the steady-state vegetation, we measured the connectivity of the bare-soil areas (Flowlength index), the patch density, and the average and standard deviation of the distance of the vegetated cells to the lattice bottom. At the patch level, we measured the average patch size, the average patch squareness (that is, the extent to which the shape of the patch resembles a quadrat, estimated as the amount of cells in the patch divided by the amount of cells in the smallest bounding or enclosing box; a squareness of 1 equals the shape of a quadrat and decreases with increasing complexity of the shape), and the average length of the upslope edge of patches (that is, the length of the patch edge that is across the slope and thus can effectively trap surface flows). We defined a vegetation patch as a group of vegetation cells connected to each other by at least one of the eight neighbouring cells.

\section{Results}

\section{On Dryland Dynamics and Catastrophic Shifts}

The combined effect of different strengths of the global and local feedbacks ( $\alpha$ and $\gamma$, respectively) shaped the degradation and recovery trajectories of steady-state vegetation cover in response to the variation in the potential plant establishment (parameter $b$, representing the quality of environmental conditions) in the simulated dryland
(Figure 3). For a gradual worsening of environmental conditions (decreasing $b$ ), an increase in the strength of the (positive) global feedback increased the risk of a sudden (discontinuous) shift to a degraded state. Increasing the strength of the global feedback also resulted in a decreasing probability of recovery from a degraded stable state with the improvement of environmental conditions (increasing $b$ ), with high strength values preventing any recovery, even for optimal environmental conditions (that is, $b=1$ ), unless combined with moderate to high strength of the local feedback. On the contrary, an increase in the strength of the local feedback increased the probability of recovery from a degraded state and allowed lower values of vegetation cover at steady state for both the degradation and the recovery pathways, preventing the occurrence of degradation regime shifts for high strength values, yet only when combined with low strengths of the global feedback. The variation in the strengths of both feedbacks had a stronger effect on the recovery than on the degradation pathway. Thus, for instance, increasing values in the strength of the local feedback hardly changed the degradation pathway for moderate-high values in the strength of the global feedback $(\alpha \geq 0.5)$, but they still increased the recovery potential. Further, increasing strengths of the global feedback combined with decreasing strengths of the local feedback increased the size of the bistability window (bistability, distance along the $\mathrm{X}$-axis between downward and upward arrows in each panel of Figure 3) and thus the range of environmental conditions for which both healthy and degraded stable states were possible. This increase in bistability was mainly due to an increase in the minimum value of environmental conditions for which recovery was possible ( $b_{\text {rec }}$, upward green arrows in Figure 3), as the threshold environmental conditions for the degradation shift $\left(b_{\mathrm{deg}}\right.$, downward grey arrows in Figure 3 ) were less sensitive to the variation in the strengths of any of the two feedbacks.

\section{On the Spatial Structure of Vegetation Cover}

For steady-state vegetation cover higher than $\approx 20-25 \%$, we did not find any effect of the different strength combinations of the global and local feedbacks on the vegetation spatial structure (results not shown). However, for lower values of vegetation cover (only stable for low strengths of the global feedback; Figure 3), and relative high strength of the local feedback, we found vegetation patches of higher average size, 


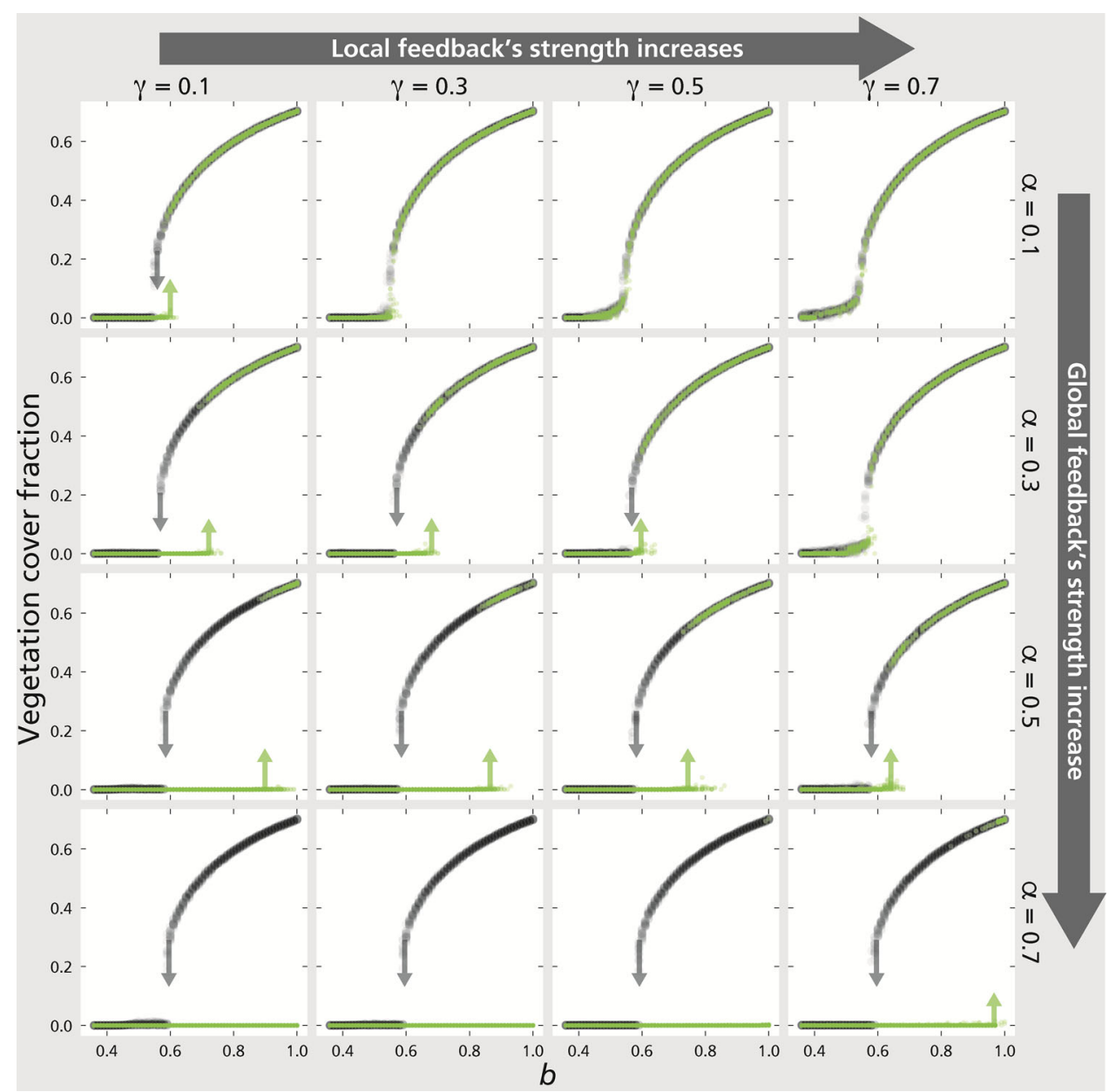

Figure 3. Equilibrium vegetation cover in relation to changing environmental conditions $(b$, a lower value represents harsher conditions) for several combinations of strengths of the global $(\alpha)$ and local $(\gamma)$ connectivity-mediated ecohydrological feedbacks along degradation and recovery pathways (grey and green circles, respectively, see data analyses section for details). Results from 20 simulation repetitions for each parameter combination. The transparency of the symbols corresponds to the frequency of the vegetation cover value (fully transparent means $0 \%$ and fully opaque means $>50 \%)$. The arrows in each panel indicate the threshold environmental conditions for degradation and recovery shifts $\left(b_{\mathrm{deg}}\right.$ and $b_{\mathrm{rec}}$, respectively), being the distance between them the range of environmental pressure that leads to bistability in the system. For parameter combinations not showing recovery under optimal environmental conditions $(b=1)$ in at least $50 \%$ of the simulation repetitions, $b_{\text {rec }}$ cannot be calculated and upward arrows are not shown. Values of the model parameters as in Table 1 (Color figure online).

less square shape, and longer upslope edge than for the model without local feedback (Figure 4A, B). Also, the vegetation patches tended to be located lower in the lattice (lower average distance of vegetated cells to the bottom row) and to form a banded pattern (lower standard deviation of the distance of vegetated cells to the bottom row) with lower bare-soil connectivity (that is, lower Flowlength) (Figure 4A, B). Because of the impact of the local connectivity on the spatial variation of plant establishment $\left(b^{\prime \prime}\right)$, plant establishment becomes highest in the lower part of the lattice and in the upper side of the patches for lower values of vegetation cover and relative high strength of the local feedback (Figure 4C).

\section{Discussion}

\section{Positive and Negative Connectivity- Mediated Feedbacks as Modulators of Regime Shifts}

Using a spatially explicit model of dryland vegetation dynamics, we showed that the interplay of two 

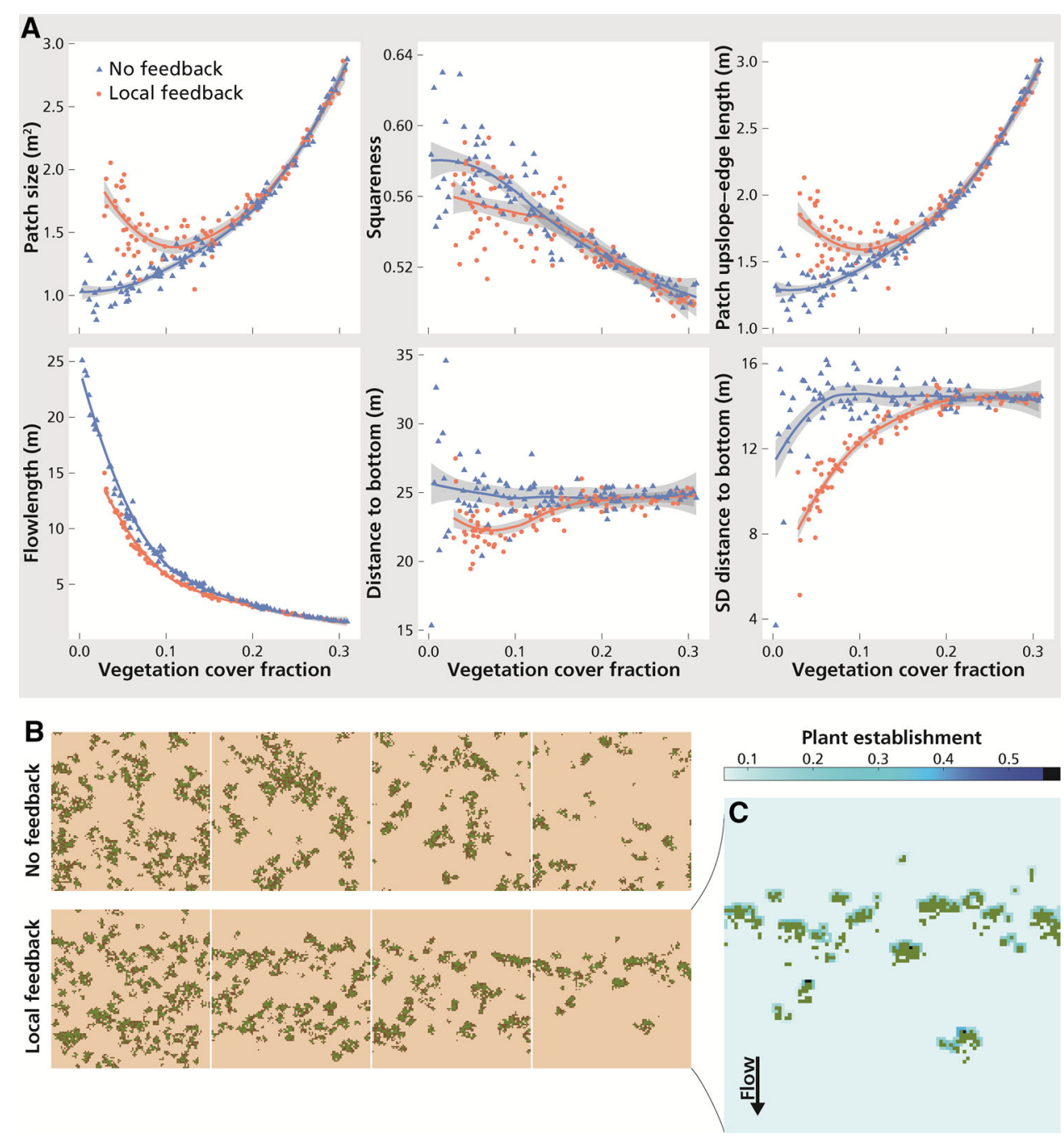

Figure 4. Impact of the local connectivity-mediated ecohydrological feedback on vegetation pattern. Examples of simulations made without connectivity feedbacks $(\alpha=0, \gamma=0$; no feedback) and with a strong local connectivity feedback $(\alpha=0, \gamma=0.7$; local feedback). A Comparison of several indicators of vegetation patchiness at the patch and landscape scales (upper and lower row, respectively). A squareness of 1 corresponds to the shape of a quadrat, and the value decreases with increasing complexity of the shape. B Snapshot of the vegetation at the end of the simulation. Green: vegetated cell. Dark brown: empty cell. Light brown: degraded cell; worsening environmental conditions from left to right: $b=0.13$, cover $=0.11 ; b=0.11$, cover $=0.08 ; b=0.08$, cover $=0.06 ; b=0.07$, cover $=0.04$. C Snapshot of plant establishment $\left(b^{\prime \prime}\right.$, blue colour gradient) and vegetated cells (green) at the end of the local feedback simulation example in (B) with cover $=0.04 . m=0.05, r=0$. Other values of the model parameters as in Table 1 (Color figure online).

simple ecohydrological feedbacks of opposite sign between vegetation cover and resource redistribution controls vegetation dynamics and modulates the transitions between healthy and degraded stable states in dryland ecosystems. Increasing strengths of a positive feedback loop between the connectivity of the bare-soil areas, the global loss of resources from the system, and the loss of vegetation cover (global feedback) decrease the resilience and the recovery potential of the ecosystem. In contrast, increasing strengths of a negative feedback loop between the connectivity of the bare-soil areas, the redistribution of resources from bare-soil areas to vegetated areas, and the local increase in vegetation cover (local feedback) decrease the risk of discontinuous transitions and facilitate the ecosystem recovery from a degraded state.

Identified as key essential mechanisms promoting shifts between alternative stable states, positive feedbacks have been the focus of most former theoretical and empirical studies on the potential for catastrophic shifts in dryland ecosystems (Schlesinger and others 1990; Rietkerk and van de Koppel 1997; Mayor and others 2013; Mora and 
Lázaro 2013; Burg and others 2014). Conversely, negative feedbacks are, when considered, only tacitly implied in most of the former studies on this topic. Negative feedbacks are omnipresent in ecosystems, playing a critical role in regulatory and stabilizing mechanisms (Rosenzweig and MacArthur 1963; Patten and Odum 1981; Soto-Ortiz 2015), yet, surprisingly, little is known about how varying strength or importance of negative feedbacks could counterbalance or reverse the amplifying effects of positive feedbacks. So far, only a few attempts have been made to explicitly consider the impacts of both types of feedbacks on dryland dynamics. Reviewing several well-known examples of state transitions in drylands, such as grassland to shrubland conversions, Briske and others (2006) and Turnbull and others (2012) proposed conceptual frameworks aimed to associate sudden transitions in ecosystem states with changes in the dominant type of the feedbacks involved (for example, self-correcting vs self-reinforcing or negative vs positive feedbacks) in response to external forcing. However, the feedbacks illustrated in those studies were in all cases positive feedbacks that varied in strength and/or direction, such as the feedbacks between frequent fires and higher grassto-shrub ratio, and between fire suppression and lower grass-to-shrub ratio, which in turn would lead to fewer fires. Both cases in that example imply positive feedback loops by which vegetation communities of both alternative states modify the same factor (that is, fire frequency), but in opposite directions (Wilson and Agnew 1992). Following a process-based modelling approach, several recent works have developed spatially explicit models that interlink vegetation and runoff source-sink dynamics (Popp and others 2009; Stewart and others 2014). The implementation of these models, particularly tailored to investigate shrub encroachment and the impact of grazing pressure and drought in arid rangelands, provided evidence for the importance of connectivity-mediated and directional processes as modulators of changes in vegetation composition and productivity. Here we developed a simpler general model that enabled us to evaluate the relative and combined roles of various strengths of positive and negative feedbacks in shaping dryland response to both increasing and decreasing environmental pressures. The model outcomes support the notion that, in general, catastrophic shifts to degraded states are less likely to occur in drylands with strong local negative ecohydrological feedbacks mediated by the hydrological connectivity of the system (that is, strong source-sink dynamics and/or strong response of vegetation growth to this resource redistribution). This result could contribute to explain the general stability found in many degraded drylands worldwide, which often maintain very low vegetation cover despite being submitted to multiple disturbances and pressures (Mora and Lázaro 2013; Berdugo and others 2017). In case of discontinuous transitions between states, strong negative feedbacks seem to largely facilitate the ecosystem recovery from a degraded stable state with very low vegetation cover, a facet of dryland dynamics much less explored in previous studies. In fact, our modelling results revealed an overall stronger impact of feedback strength on the recovery than on the degradation trajectory. This asymmetry probably relates to the general nonlinear increase in hydrological connectivity with decreasing vegetation (Rodríguez and others 2018) and, thus, to the stronger importance of the connectivity-mediated feedbacks for small values of vegetation cover, which are more likely in the recovery trajectories. This is supported by field data from Mediterranean drylands that showed more intense effects of runoff redistribution from bare soils to plant patches for low than for high hillslope vegetation cover (Espigares and others 2013).

\section{On the Strength of Connectivity- Mediated Feedbacks}

Important and challenging questions to be answered include the factors that influence the strength of the connectivity-mediated positive and negative ecohydrological feedbacks ( $\alpha$ and $\gamma$ in our model), and the set of conditions that would lead to a higher strength of the local negative feedback relative to the global positive one, provided that both types are mediated by changes in bare-soil connectivity. Furthermore, there is still very limited empirical knowledge on the type of functions that would better describe the links between the different components of the feedback loops. For example, the well-documented linear increase in runoff with the increase in bare-soil connectivity (Bautista and others 2007; Ludwig and others 2007; Mayor and others 2008) contrasts with the lack of information on how this increase in runoff would in turn affect plant biomass production and on how runoff inputs from bare-soil areas would modulate the growth of the downslope vegetation patches. Based on the linear relationships between rainfall and plant biomass most commonly reported for dryland landscapes (for example, Du Plessis 1999; Zhu and Southworth 2013; Salimon and Anderson 2017), we adopted the parsimonious 
assumption of linear changes in plant establishment in response to changes in resource availability driven by runoff redistribution and losses. We used, however, a saturation function relating plant establishment and local connectivity to simulate the limited sink capacity of vegetation patches (Puigdefabregas and others 1999; Ludwig and others 2005; Mayor and others 2009). With the current parameterization of the model (that is, lattice of $100 \times 100$ cells of size $0.5 \times 0.5 \mathrm{~m}^{2}$ on a planar slope with an angle of $20^{\circ}$, and $1 / 3$ in Eq. 7), this "saturation" of the local feedback occurs for bare-soil lengths of approximately $17 \mathrm{~m}$ (that is, slope length/3), which is a conservative assumption relative to the few data available on the relationship between plant performance and upslope runoff-contributing area (Urgeghe and Bautista 2015).

Regardless of the type of relationship between plant establishment and runoff-driven resource gains and losses, a variety of abiotic and biotic factors could modulate the strength of the global and local connectivity-mediated feedbacks, which could therefore vary across ecosystem types and environmental gradients. Thus, large and/or intense rainfalls, surface-compacted soils, and steep slopes favour more frequent and higher runoff events with longer runoff pathways (for example, Mayor and others 2008; Magliano and others 2015), potentially increasing the strength of both the global and the local feedbacks. However, once the sink capacity of the plant patches saturates, further increases in runoff amount or length would only increase the strength of the global feedback. Similarly, soils prone to erosion and rill formation could promote microtopography changes that divert runoff around vegetation patches (Chen and others 2013), decreasing the runoff-driven inputs to the patch and in turn increasing the strength of the global feedback. In this way, the role of a number of factors that have been previously identified as facilitators of dryland degradation can be explained in terms of their contribution to enhance the importance of the global positive ecohydrological feedback relative to the local negative one.

The biotic controls of the strength of the connectivity-mediated feedbacks relate to plant traits that could modulate the efficiency of plant patches in capturing and storing runoff-driven resources, and the response of the plant species to variations in resource availability. In general, plants with dense ground cover and thick litter layers are most efficient at capturing runoff (Mayor and others 2009), which contributes to increase the relative strength of the local feedback. However, plant growth can only benefit from runoff inputs and thereby contribute to the local negative feedback, when the resulting increase in soil moisture occurs at depths that coincide with the bulk of the plant root system. In this way, shallow-rooted plants such as grasses or small shrubs would reinforce the local negative feedback, when combined with conditions leading to shallow wetting fronts from runoff inputs (Pockman and Small 2010), while deep-rooted plants such as tall shrubs would increase the strength of the local feedback for conditions leading to deeper wetting fronts (MorenoGutiérrez and others 2012), conditions that can also be promoted by the shrub root system (Puigdefabregas and others 1999; Whitford 2002). Expected climatic changes towards more concentrated rainfalls in dryland regions (IPCC 2014) may result in deeper soil wetting and thus in a competitive advantage for deep-rooted relative to shallow-rooted species (Yu and others 2017), particularly if deep roots combine with traits that enhance the efficiency in capturing runoff. Rooting depth and water-use strategies of the species would also affect the response of the plant species to decreasing effective rainfall (for example, due to increasing runoff-driven losses), with shallowrooting and isohydric species exhibiting the most constrained growth in case of increasing dryness (Mcdowell and others 2008; West and others 2012), and therefore the highest potential to reinforcing the global positive feedback towards degradation. Nevertheless, there is further complexity to consider as large variability in resource use is also possible between coexisting grasses, coexisting shrubs, or mixed patches with shrubs and grasses (Gebauer and others 2002; Huxman and others 2008; Moreno-Gutiérrez and others 2012). Actually, empirical evidence on how wateruse trade-offs influence the structure of dryland communities is still rather limited and a topic of active research (Shriver 2017).

\section{Impact of Connectivity-Mediated Feedbacks on Vegetation Pattern}

The local connectivity (bare-soil connectivity of upslope vegetation patches) has a clear directional influence on the spatial variation of plant establishment, which is generally enhanced in the upslope side of the patches. As predicted by the model, a higher strength of the local feedback promoted a higher degree of anisotropy in the vegetation pattern. Thus, under a dominance of the local connectivity-mediated feedback and low vegetation cover, the model predicts fewer and larger vegetation patches elongated across slope, 
and therefore with higher potential for breaking the global hydrological connectivity. Due to the influence of local facilitation (Kéfi and others 2007b) and runoff-driven resource inputs, local colonization of any given bare-soil area is higher when neighbouring areas are both vegetated and with high upslope bare-soil connectivity, which facilitates the generation of banded patterns. This effect of local connectivity on the vegetation pattern is only observed for small values of vegetation cover, which is clearly consistent with the fact that the effects of the connectivity-mediated feedbacks are most relevant at low cover values. Vegetation bands perpendicular to the slope are common in healthy states of regular vegetation patterns (Deblauwe and others 2008), yet they have also been observed in irregular patterns (that is, without characteristic patch size) like those predicted by our model, especially in situations with low vegetation cover and high surface redistribution of runoff and sediments (Cammeraat and Imeson 1999; Boer and Puigdefábregas 2005). The distance between vegetation bands would reflect the runoff redistribution length that optimizes plant performance. As suggested by Puigdefabregas and others (1999) in their seminal work on water and sediment redistribution processes, vegetation patches would negatively affect downslope patches located at a shorter distance than the optimal redistribution length and plant patterns would partly reflect patterns of competition intensity for runoff water.

Contrary to the influence of the local connectivity feedback, the loss of resources mediated by the global bare-soil connectivity is assumed to decrease the overall potential for plant establishment homogeneously across space, as it basically entails a decrease in effective rainfall. However, due to the directional nature of connectivity (it follows topographic gradients), we could expect a relative accumulation of resources towards lower slope positions (Law and others 2012). Although we did not consider this gradient in our model, its most probable effect would be an increase in the probability of plant establishment on the lowest position of the slopes and thus a further increase in the anisotropy of the vegetation pattern.

\section{Implications for Dryland Restoration}

Suding and others (2004) were pioneers in proposing a framework linking alternative ecosystem state theory to restoration ecology. In that work, the authors highlighted that positive feedbacks can make a degraded system resilient to restoration and that the disruption of these feed- backs was needed to re-establish ecosystem function and resilience. Following on this idea and the outputs of our model, we propose that restoration strategies for the recovery of degraded drylands should focus on manipulating the connectivitymediated feedbacks by disrupting the global positive feedback while increasing the strength of the local negative feedback. Breaking the positive feedback between resource loss and vegetation loss can be successfully achieved by applying a simple restoration strategy: placing piles of branches regularly spaced and following contour lines on the target degraded slopes (Ludwig and Tongway 1996; Kimiti and others 2017). Similarly, arranging planted or seeded vegetation in a staggered pattern contributes to reduce the global bare-soil connectivity of the area and in turn maximizes the local bare-soil connectivity to the whole set of introduced vegetation patches. The benefits of the redistribution of resources from bare-soil to vegetation patches, one of the processes included in the local feedback, have long been exploited for restoration purposes by means of runoff-harvesting techniques (Bainbridge 2007; Paz-Kagan and others 2017). More recently, a number of plantation techniques that recreate the sink function of vegetation patches, decrease the runoff generation threshold, and/or redirect runoff towards the planting hole, have proven successful in improving survival and growth of introduced seedlings, particularly in sites with high bare-soil connectivity and thus high potential for runoff redistribution, which is the most common case in degraded areas (Urgeghe and Bautista 2015; Fuentes and others 2017).

The local feedback could also be strengthened by creating plant patches with species mixes that combine shallow- and deep-rooted systems and morphologies that facilitate trapping and redirecting runoff water towards deeper soil layers such as dense ground cover and V-shaped canopies, respectively. In this way, the capture and deep infiltration of the extra runoff water generated in large bare-soil areas is maximized (Mayor and others 2009), which in turn would enhance plant growth. Deep-rooting tall shrubs with dense canopies and thick litter layers have a great potential for ameliorating environmental conditions and also fostering local facilitation (Soliveres and others 2014), thus further decreasing the risk of state transitions (Kéfi and others 2007b). To the best of our knowledge, increasing the strength of the local feedback by manipulating the biotic structure of the community, applied independently or in combination with actions that disrupt the global feed- 
back, has never been tested as a restoration strategy. However, there is an increasing attention on the role of fine-scale planting arrangements in fostering the recovery of ecosystem functions, including water and nutrient capture (McCallum and others 2018). Interestingly, our modelling results point to a higher sensitivity of the recovery pathways to the interplay of the feedbacks, which suggests that the manipulation of the connectivitymediated feedbacks could be particularly useful to increase restoration success in degraded drylands.

\section{Conclusions}

We proposed a new conceptual and modelling framework for the study of dryland regime shifts that integrates two connectivity-mediated ecohydrological feedbacks of opposite sign and that operate at different scales: a global positive feedback and a local negative feedback between changes in bare-soil connectivity and vegetation growth at the ecosystem and at the vegetation patch scales, respectively. We used this framework to evaluate the interplay of varying strengths of positive and negative feedbacks on dryland response to environmental pressure, which has seldom been investigated. Our findings suggest that catastrophic regime shifts to degraded states are less likely in drylands with strong local negative feedbacks between vegetation cover and runoff-driven redistribution of resources from bare-soil areas to vegetated patches. Further, even in case of discontinuous transitions between healthy and degraded ecosystem states, strong negative feedbacks seem to largely facilitate the recovery of degraded states with very low vegetation cover. These results point to the potential of feedback manipulation for dryland restoration by designing strategies that disrupt the global feedback while increasing the strength of the local feedback. Knowledge on the manipulation of the strength of these feedbacks might be a sufficient first step to aid restoration even if we cannot predict if the ecosystem corresponds to a threshold model with or without hysteresis. However, defining the strength of these feedbacks is still very challenging due to the limited empirical knowledge on the functional forms describing the links between some of the feedbacks components and on the importance of the multiple factors that may affect the feedback strength. Finally, our model is able to represent the increasing anisotropy of irregular vegetation patterns observed in drylands in situations of low vegetation cover and high redistribution of resources. This pattern effect is more likely to occur in drylands with strong negative ecohydrological feedbacks and, thus, with a higher recovery potential.

\section{ACKNOWLEDGMENTS}

This work was supported by the research Projects DRYEX (CGL2014-59074-R) and DRYEX2 (CGL2017-89804-R), funded by the Spanish Ministry of Economy and Competitiveness, and the ECfunded Project CASCADE (GA283068). FR and SB acknowledge the financial support from the "Programa Estatal de Promoción del Talento y su Empleabilidad en I + D+i, Subprograma Estatal de Movilidad, del Plan Estatal de Investigación Científica y Técnica y de Innovación 2013-2016" (PRX14/00691 and PRX16/00583), funded by the Spanish Ministry of Education, Culture and Sports (MECD). FR also acknowledges the financial support from the Valencia Regional Government, Generalitat Valenciana (BEST/2014/285). AGM was supported by the EC-funded Marie Skłodowska-Curie Action ECOHYDRY (GA660859).

\section{OPEN ACCESS}

This article is distributed under the terms of the Creative Commons Attribution 4.0 International License (http://creativecommons.org/licenses/by/4 $.0 /$ ), which permits unrestricted use, distribution, and reproduction in any medium, provided you give appropriate credit to the original author(s) and the source, provide a link to the Creative Commons license, and indicate if changes were made.

\section{REFERENCES}

Bainbridge DA. 2007. A guide for desert and dryland restoration: new hope for arid lands. Washington, DC: Island Press.

Bautista S, Mayor ÁG, Bourakhouadar J, Bellot J. 2007. Plant spatial pattern predicts hillslope runoff and erosion in a semiarid mediterranean landscape. Ecosystems 10:987-98.

Berdugo M, Kéfi S, Soliveres S, Maestre FT. 2017. Plant spatial patterns identify alternative ecosystem multifunctionality states in global drylands. Nat Ecol Evol 1:0003.

Bestelmeyer BT, Ellison AM, Fraser WR, Gorman KB, Holbrook SJ, Laney CM, Ohman MD, Peters DPC, Pillsbury FC, Rassweiler A, Schmitt RJ, Sharma S. 2011. Analysis of abrupt transitions in ecological systems. Ecosphere 2:art129.

Boer M, Puigdefábregas J. 2005. Effects of spatially structured vegetation patterns on hillslope erosion in a semiarid Mediterranean environment: a simulation study. Earth Surf Process Landf 30:149-67.

Briske DD, Fuhlendorf SD, Smeins FE. 2006. A unified framework for assessment and application of ecological thresholds. Rangel Ecol Manag 59:225-36.

Burg D, Malkinson D, Katriel G, Wittenberg L. 2014. Modeling the dynamics of soil erosion and vegetative control-catastrophe and hysteresis. Theor Ecol 8:67-79. 
Callaway RM. 2007. Positive interactions and interdependence in plant communities. Berlin: Springer.

Cammeraat LH, Imeson AC. 1999. The evolution and significance of soil-vegetation patterns following land abandonment and fire in Spain. Catena 37:107-27.

Chen L, Sela S, Svoray T, Assouline S. 2013. The role of soilsurface sealing, microtopography, and vegetation patches in rainfall-runoff processes in semiarid areas. Water Resour Res 49:5585-99. http://doi.wiley.com/10.1002/wrcr.20360. Accessed 20 Aug 2016

Davenport DW, Breshears DD, Wilcox BP, Allen CD. 1998. Viewpoint: sustainability of pinon-juniper ecosystems: a unifying perspective of soil erosion thresholds. J Range Manag 51:231.

DeAngelis D, Post WM, Travis CC. 1986. Positive feedback in natural systems. 1st edn. Berlin: Springer.

Deblauwe V, Barbier N, Couteron P, Lejeune O, Bogaert J. 2008. The global biogeography of semi-arid periodic vegetation patterns. Glob Ecol Biogeogr 17:715-23.

Du Plessis WP. 1999. Linear regression relationships between NDVI, vegetation and rainfall in Etosha National Park, Namibia. J Arid Environ 42:235-60.

Espigares T, Merino-Martín L, Moreno-de Las Heras M, Nicolau JM. 2013. Intensity of ecohydrological interactions in reclaimed Mediterranean slopes: effects of run-off redistribution on plant performance. Ecohydrology 6:836-44.

Fuentes D, Smanis A, Valdecantos A. 2017. Recreating sink areas on semiarid degraded slopes by restoration. Land Degrad Dev 28:1005-15.

Gao Y, Zhong B, Yue H, Wu B, Cao S. 2011. A degradation threshold for irreversible loss of soil productivity: a long-term case study in China. J Appl Ecol 48:1145-54.

García-Fayos P, Bochet E, Cerdà A. 2010. Seed removal susceptibility through soil erosion shapes vegetation composition. Plant Soil 334:289-97.

Gebauer RLE, Schwinning S, Ehleringer JR. 2002. Interspecific competition and resource pulse utilization in a cold desert community. Ecology 83:2602-16.

Huxman TE, Barron-Gafford G, Gerst KL, Angert AL, Tyler AP, Venable DL. 2008. Photosynthetic resource-use efficiency and demographic variability in desert winter annual plants. Ecology 89:1554-63.

IPCC. 2014. Climate Change 2014: Synthesis report. In Pachauri RK, Meyer LA, Eds. Contrib Work Groups I, II III to Fifth Assessment Report Intergovernmental Panel on Climate Chang Core Write Team. Geneva: IPCC. p 151.

Kéfi S, Holmgren M, Scheffer M. 2016. When can positive interactions cause alternative stable states in ecosystems? Funct Ecol 30:88-97.

Kéfi S, Rietkerk M, Alados CL, Pueyo Y, Papanastasis VP, Elaich A, De Ruiter PC. 2007a. Spatial vegetation patterns and imminent desertification in Mediterranean arid ecosystems. Nature 449:213-18.

Kéfi S, Rietkerk M, van Baalen M, Loreau M. 2007b. Local facilitation, bistability and transitions in arid ecosystems. Theor Popul Biol 71:367-79.

Kimiti DW, Riginos C, Belnap J. 2017. Low-cost grass restoration using erosion barriers in a degraded African rangeland. Restor Ecol 25:376-84.

King EG, Franz TE, Caylor KK. 2012. Ecohydrological interactions in a degraded two-phase mosaic dryland: Implications for regime shifts, resilience, and restoration. Ecohydrology 5:733.

Law DJ, Breshears DD, Ebinger MH, Meyer CW, Allen CD. 2012. Soil $\mathrm{C}$ and $\mathrm{N}$ patterns in a semiarid piñon-juniper woodland: topography of slope and ephemeral channels add to canopyintercanopy heterogeneity. J Arid Environ 79:20-4.

Lejeune O, Tlidi M, Couteron P. 2002. Localized vegetation patches: a self-organized response to resource scarcity. Phys Rev E Stat Nonlinear Soft Matter Phys 66:4.

Lenton TM. 2013. Environmental tipping points. Annu Rev Environ Resour 38:1-29.

Liu Y, Fu B, Lü Y, Gao GY, Wang S, Zhou J. 2013. Linking vegetation cover patterns to hydrological responses using two process-based pattern indices at the plot scale. Sci China Earth Sci 56:1888-98.

Ludwig J, Wilcox BP, Breshears DD, Tongway DJ, Imeson AC. 2005. Vegetation patches and runoff-erosion as interacting ecohydrological processes in semiaris landscapes. Ecology 86:288-97.

Ludwig JA, Bastin GN, Chewings VH, Eager RW, Liedloff AC. 2007. Leakiness: a new index for monitoring the health of arid and semiarid landscapes using remotely sensed vegetation cover and elevation data. Ecol Indic 7:442-54.

Ludwig JA, Tongway DJ. 1996. Rehabilitation of semiarid landscapes in Australia. II. Restoring vegetation patches. Restor Ecol 4:398-406.

Magliano PN, Breshears DD, Fernández RJ, Jobbágy EG. 2015. Rainfall intensity switches ecohydrological runoff/runon redistribution patterns in dryland vegetation patches. Ecol Appl 25:2094-100.

May RM. 1977. Thresholds and breakpoints in ecosystems with a multiplicity of stable states. Nature 260:471-7.

Mayor ÁG, Bautista S, Bellot J. 2009. Factors and interactions controlling infiltration, runoff, and soil loss at the microscale in a patchy Mediterranean semiarid landscape. Earth Surf Process Landf 34:1702-11.

Mayor ÁG, Bautista S, Small EEE, Dixon M, Bellot J. 2008. Measurement of the connectivity of runoff source areas as determined by vegetation pattern and topography: a tool for assessing potential water and soil losses in drylands. Water Resour Res 44:1-13.

Mayor ÁG, Kéfi S, Bautista S, Rodríguez F, Cartení F, Rietkerk M. 2013. Feedbacks between vegetation pattern and resource loss dramatically decrease ecosystem resilience and restoration potential in a simple dryland model. Landsc Ecol 28:931-42.

McCallum KP, Lowe AJ, Breed MF, Paton DC. 2018. Spatially designed revegetation - why the spatial arrangement of plants should be as important to revegetation as they are to natural systems. Restor Ecol 1:8. https://doi.org/10.1111/rec.12690.

Mcdowell N, Pockman WT, Allen CD, Breshears DD, Cobb N, Kolb T, Plaut J, Sperry J, West A, Williams DG, Yepez EA, Mcdowell N, Pockman WT, Allen CD, David D, Mcdowell N, Cobb N, Kolb T, Plaut J, Sperry J. 2008. Mechanisms of plant survival and mortality during drought: why do some plants survive while others succumb to drought? New Phytol 178:719-39.

MEA. 2005. Ecosystems and human well-being: health synthesis. Millenium Ecosyst Assess 5:64.

Meron E. 2016. Pattern formation-a missing link in the study of ecosystem response to environmental changes. Math Biosci 271:1-18. 
Middleton NJ, Sternberg T. 2013. Climate hazards in drylands: a review. Earth Sci Rev 126:48-57.

Mora JL, Lázaro R. 2013. Evidence of a threshold in soil erodibility generating differences in vegetation development and resilience between two semiarid grasslands. J Arid Environ 89:57-66.

Moreno-Gutiérrez C, Dawson TE, Nicolás E, Querejeta JI. 2012. Isotopes reveal contrasting water use strategies among coexisting plant species in a mediterranean ecosystem. New Phytol 196:489-96.

Muñoz-Robles C, Tighe M, Reid N, Frazier P, Briggs SV, Wilson B. 2013. A two-step up-scaling method for mapping runoff and sediment production from pasture and woody encroachment on semi-arid hillslopes. Ecohydrology 6:83-93.

Okin GS, De Las Heras MM, Saco PM, Throop HL, Vivoni ER, Parsons AJ, Wainwright J, Peters DPC. 2015. Connectivity in dryland landscapes: Shifting concepts of spatial interactions. Front Ecol Environ 13:20-7.

Otterman J. 1977. Anthropogenic impact on the albedo of the earth. Clim Change 1:137-55.

Patten BC, Odum EP. 1981. The cybernetic nature of ecosystems. Am Nat 118:886-95.

Paz-Kagan T, Ohana-Levi N, Shachak M, Zaady E, Karnieli A. 2017. Ecosystem effects of integrating human-made runoffharvesting systems into natural dryland watersheds. J Arid Environ 147:133-43.

Pockman WT, Small EE. 2010. The influence of spatial patterns of soil moisture on the grass and shrub responses to a summer rainstorm in a Chihuahuan desert ecotone. Ecosystems 13:511-25.

Popp A, Vogel M, Blaum N, Jeltsch F. 2009. Scaling up ecohydrological processes: role of surface water flow in water-limited landscapes. J Geophys Res Biogeosci 114:4.

Prăvălie R. 2016. Drylands extent and environmental issues. A global approach. Earth Sci Rev 161:259-78.

Puigdefabregas J, Sole A, Gutierrez L, Del Barrio G, Boer M. 1999. Scales and processes of water and sediment redistribution in drylands: results from the Rambla Honda field site in Southeast Spain. Earth Sci Rev 48:39-70.

Rietkerk M, Dekker SC, de Ruiter PC, van de Koppel J. 2004. Self-organized patchiness and catastrophic shifts in ecosystems. Science (80-) 305:1926-9.

Rietkerk M, Ketner P, Stroosnijder L, Prins HHT. 1996. Sahelian rangeland development; a catastrophe? J Range Manag 49:512-19.

Rietkerk M, van de Koppel J. 1997. Alternative stable states and threshold effects in semi-arid grazing systems. Oikos 79:6976.

Rietkerk M, van de Koppel J. 2008. Regular pattern formation in real ecosystems. Trends Ecol Evol 23:169-75.

Rodriguez-Iturbe I. 2000. Ecohydrology: a hydrologic perspective of climate-soil-vegetation dynamics. Water Resour Res 36:3-9.

Rodríguez F, Mayor ÁG, Rietkerk M, Bautista S. 2018. A null model for assessing the cover-independent role of bare soil connectivity as indicator of dryland functioning and dynamics. Ecol Indic 94:512-19.

Rosenzweig ML, MacArthur RH. 1963. Graphical representation and stability conditions of predator-prey interactions. Am Nat 97:209-23.

Salimon C, Anderson L. 2017. How strong is the relationship between rainfall variability and Caatinga productivity? a case study under a changing climate. Ann Brazilian Acad Sci Press 90:2121.

Scheffer M. 2009. Critical transitions in nature and society. Princet Stud Complex 16:384.

Scheffer M, Carpenter S, Foley JA, Folke C, Walker B. 2001. Catastrophic shifts in ecosystems. Nature 413:591-6.

Scheffer M, Carpenter SR. 2003. Catastrophic regime shifts in ecosystems: linking theory to observation. Trends Ecol Evol 18:648-56.

Schlesinger WH, Reynolds JF, Cunningham GL, Huenneke LF, Jarrell WM, Virginia RA, Whitford WG. 1990. Biological feedbacks in global desertification. Science 247:1043-8.

Shriver RK. 2017. Rainfall variability and fine-scale life history tradeoffs help drive niche partitioning in a desert annual plant community. Ecol Lett 20:1231-41.

Soliveres S, Maestre FT, Bowker MA, Torices R, Quero JL, García-Gómez M, Cabrera O, Cea AP, Coaguila D, Eldridge DJ, Espinosa CI, Hemmings F, Monerris JJ, Tighe M, DelgadoBaquerizo M, Escolar C, García-Palacios P, Gozalo B, Ochoa V, Blones J, Derak M, Ghiloufi W, Gutiérrez JR, Hernández RM, Noumi Z. 2014. Functional traits determine plant co-occurrence more than environment or evolutionary relatedness in global drylands. Perspect Plant Ecol Evol Syst 16:164-73.

Soto-Ortiz L. 2015. The regulation of ecological communities through feedback loops: a review. Res Zool 5:1-15.

Stewart J, Parsons AJ, Wainwright J, Okin GS, Bestelmeyer BT, Fredrickson EL, Schlesinger WH. 2014. Modeling emergent patterns of dynamic desert ecosystems. Ecol Monogr 84:373410.

Suding KN, Gross KL, Houseman GR. 2004. Alternative states and positive feedbacks in restoration ecology. Trends Ecol Evol 19:46-53. https://doi.org/10.1016/j.tree.2003.10.005.

Svejcar LN, Bestelmeyer BT, Duniway MC, James DK. 2014 Scale-dependent feedbacks between patch size and plant reproduction in desert grassland. Ecosystems 18:146-53.

Turnbull L, Wainwright J, Brazier RE. 2010. Changes in hydrology and erosion over a transition from grassland to shrubland. Hydrol Process 24:393-414.

Turnbull L, Wilcox BP, Belnap J, Ravi S, D'Odorico P, Childers D, Gwenzi W, Okin G, Wainwright J, Caylor KK, Sankey T. 2012. Understanding the role of ecohydrological feedbacks in ecosystem state change in drylands. Ecohydrology 5:17483.

Urgeghe AM, Bautista S. 2015. Size and connectivity of upslope runoff-source areas modulate the performance of woody plants in Mediterranean drylands. Ecohydrology 8:1292-303.

Urgeghe AM, Breshears DD, Martens SN, Beeson PC. 2010. Redistribution of runoff among vegetation patch types: on ecohydrological optimality of herbaceous capture of run-on. Rangel Ecol Manag 63:497-504.

von Hardenberg J, Meron E, Shachak M, Zarmi Y. 2001. Diversity of vegetation patterns and desertification. Phys Rev Lett 87:198101-1-4.

Waddington JM, Morris PJ, Kettridge N, Granath G, Thompson DK, Moore PA. 2015. Hydrological feedbacks in northern peatlands. Ecohydrology 8:113-27.

West AG, Dawson TE, February EC, Midgley GF, Bond WJ, Aston TL. 2012. Diverse functional responses to drought in a Mediterranean-type shrubland in South Africa. New Phytol 195:396-407.

Whitford W. 2002. Ecology of desert systems. San Diego: Academic Press. 
Wilson JB, Agnew ADQ. 1992. Positive-feedback switches in plant communities. Adv Ecol Res 23:263-336.

Yu K, Saha MV, Odorico PD. 2017. The effects of interannual rainfall variability on tree-grass composition along Kalahari rainfall gradient. Ecosystems 20:975-88.
Zhu L, Southworth J. 2013. Disentangling the relationships between Net primary production and precipitation in Southern Africa savannas using satellite observations from 1982 to 2010. Remote Sens 5:3803-25. 